\title{
Internal Disc Disruption and Low Back Pain
}

\author{
Nalini Sehgal, MD*, Joseph D. Fortin, DO**
}

Internal disc disruption is a common cause of disabling low back pain in a substantial number of young, healthy adults. Crock described this painful entity and reported annular fissures that distort the internal architecture of the disc; Externally the disc appears relatively intact and undeformed. A clinical diagnosis of internal disc disruption, in absence of objective clinical findings, is extremely difficult. The only convincing means to establish the diagnosis is provocation discography. Unfortunately, this procedure is controversial, making the existence of internal disc disruption suspect. Recent studies indicate the existence of a biochemical/

Chronic low back pain is the leading cause of work-related disability in people under age 45 (1-4). Only a small proportion $(<15 \%)$ will have an underlying nerve-root compromise secondary to a herniated disc $(5,6)$. The majority $(85 \%)$ have non-neurogenic low back pain $(3,7)$ and a significant proportion of these patients are assumed to be related to musculoligamentous injury or degenerative changes (8).

It is surprising that, even though $85 \%$ have a non-neurogenic cause for low back pain, no attempt is made to arrive at a specific diagnosis. Nonspecific diagnoses such as lumbar strain/sprain or low back pain of unknown origin are very common $(3,8)$. The accepted dictum is that diagnostic efforts to search for a specific pathoanatomic cause will be disappointing; and, therefore, instead of searching for one, it is more useful to ensure that there is no serious underlying systemic disease, and no evidence of neurologic compromise that might require surgical intervention (8). However, it is well recognized that only $2 \%$ of disc

From Spine Technology and Rehabilitation, Fort Wayne, Indiana. * Dr. Sehgal is a Fellow at Spine Technology and Rehabilitation. ** Dr. Fortin is medical director at Spine Technology and Rehabilitation and Clinical Assistant Professor of Rehabilitation Medicine at Indiana University School of Medicine. Address correspondence: Joseph Fortin, DO, 7230 Engle Road, Suite 210, Fort Wayne, IN 46804 biomechanical model of discogenic pain, which explains the disabling low back pain in some subjects with no objective evidence of nerve-root compromise. However, a reluctance to acknowledge internal disc disruption as a valid clinical entity delays diagnosis and treatment. Failure to identify and treat this entity early and aggressively results in longterm disability, thereby perpetuating the enigma of chronic low back pain.

Keywords: Internal disc disruption, chronic low back pain, discography

herniations need surgery (5), $4 \%$ have compression fractures, $0.7 \%$ have spinal malignant neoplasms and even fewer have ankylosing spondylitis $(0.3 \%)$ or spinal infection $(0.01 \%)(5)$.

One commonly overlooked source of chronic low back pain is internal disruption of the lumbar intervertebral disc (9). A disc can cause back and lower-limb pain independent of nerve-root compromise. This concept of disc-mediated somatic pain has not yet gained unanimous approval (10), even though the disc has been suspected to be a potential pain generator for several years (11-14). Crock (14) coined the term internal disc disruption and described the pathologic features of this painful entity. He reported loss of normal distinction between the nucleus pulposus and the annulus fibrosus, gross disorganization and fissuring of the annulus, preserved external disc contour and appearance, and absence of nerve-root compression. Such a disc appeared externally intact and undeformed on computed tomographic (CT) scan and myelograms but revealed painful annular pathology on discography. Diagnostic disc injection, the sole direct method of distinguishing symptomatic from asymptomatic discs, has, however, been a subject of controversy (10).

The idea that a small fissure in the annulus incites a biochemical process causing substantial back pain is revolutionary and provokes much debate. It challenges the popular and deeply ingrained belief that a disc lesion can only cause pain by direct nerve compression from disc pro- 
lapse. As our thought process evolves to accept the biochemical model of discogenic pain, we will be more willing to identify and treat subjects with low back pain from internal disc disruption. Scant information and lack of wellcontrolled studies contribute to the reluctance to accept internal disc disruption as a valid clinical entity.

In light of available literature, this article attempts to explain the structure and function of a healthy intervertebral disc, outlines some of the known biochemical and biomechanical factors involved in disc disruption, discusses the pathomechanics of pain and correlates information obtained from basic science research to established/innovative diagnostic and therapeutic approaches to internal disc disruption.

\section{HISTORICAL BACKGROUND}

For decades after Mixter and Barr's (15) hallmark description of herniated nucleus pulposus, physicians fixated on the neurocompressive model of the disc as the cardinal cause of spine pain. A disc was perceived as capable of generating back/leg pain only by mechanical nerve-root compression, as seen with herniated discs. As a result aggressive spine surgery was frequently recommended for low back pain.

An increasing number of surgical failures prompted efforts to improve diagnostic accuracy and search for other causes of spine pain (16). Dandy in 1941 had alluded to his disillusionment at failing to detect herniated nucleus pulposus in an overwhelming percentage of patients with recurring attacks of low back pain and leg symptoms (11). He believed that in a large majority of these patients the source of pain was a concealed ruptured disc. Fernstrom (1960) observed that a simple, ruptured disc without herniation can have a clinical presentation similar to herniated nucleus pulposus (17). Pain from these discs had a deep somatic and a referred lower-extremity component.

Interest in the disc as an independent pain generator was sparked by the discovery of Hirsch (1948), who noted relief of sciatic pain following intradiscal injection of novocaine into the disc (12). Smythe and Wright (18) attached nylon threads to potential pain generators such as ligamentum flavum, interspinal ligament, dura, nerve roots, and annulus during surgery on herniated discs. Traction on the threads attached to the annulus elicited back pain, while nerve-root stimulation caused sciatic pain. Others reported back pain with mechanical disc stimulation at surgery and intradiscally on discography (17).
Even though the innervation of annulus fibrosus had been described in 1940 by Roofe (19), it took nearly 50 years to correlate painful provocation response on discography to annular fissures extending into mid and outer annulus (20). Lindblom (21) had demonstrated, in 1944, radial annular fissures on disc injections in cadavers and later described nucleographic patterns of 15 discs in 13 patients. Unfortunately discography was rejected as a valid diagnostic tool following the wide publicity of Holt's study (22) that reported false-positive rates of $37 \%$ for lumbar and $100 \%$ for cervical disc injections in asymptomatic prison inmates. Holt's data were later shown to be flawed by poor selection, technical inadequacies, and fallacious interpretation $(23,24)$.

Advances in imaging technology (magnetic resonance imaging \& CT imaging) have provided new insights into disc pathology. This has allowed recognition of changes in disc contour, hydration and architecture but has not helped with understanding the clinical significance of these abnormalities, or in isolating the pain generator. Reports of incidental disc abnormalities such as disc bulge/protrusion in $30 \%$ to $50 \%$ of asymptomatic adults (25-27) suggests that a degenerated disc does not always equate with a painful disc. It is obvious now that a diagnosis based on MRI/CT abnormalities alone, without supportive objective clinical evidence, may not identify the cause of low back pain. Overdiagnosing and overtreating clinically insignificant structural abnormalities are a real concern (28).

Equally disconcerting are the large number of chronic low back pain subjects with painful, albeit normal-looking discs (9). What makes a relatively normal-looking/degenerate disc painful and yet another grossly degenerate disc painless continues to perplex. Experimental data point to the immunogenic potential of the nucleus pulposus (29-31). Biochemical studies on normal and degenerated discs have shed light on the mechanism of discogenic pain $(29,32$, 33). How structural and biochemical changes in the disc relate to discogenic pain is still not completely understood. It is but natural that, unless these mysteries are unraveled, the clinical course and treatment of internal disc disruption will continue to be a dilemma.

\section{STRUCTURE}

Can the intervertebral disc, a cartilaginous structure sandwiched between the flat surfaces of adjacent vertebral bodies, allow motion without compromising stability, strength or weight-bearing capacity? The disc is an interbody joint that transmits load and preserves stability and strength 
through the entire range of lumbar motion. A basic understanding of disc structure, biochemistry and biomechanical properties is essential for appreciating disc function under normal and abnormal circumstances.

\section{Morphology}

Each disc is a biconvex structure consisting of a central semifluid, gelatinous mass, the nucleus pulposus, an outer ring of collagen fibers, the annulus fibrosus, and two cartilaginous end plates that attach the disc to the vertebral body. The annulus is lamellated; there are 10 to 12 overlapping concentric lamellae of collagen fibers that alternatively incline at 65 to 70 degrees from the vertical, such that every second lamella has exactly the same orientation. Superficial lamellae at the periphery of the disc insert directly into the vertebral body, while the fibers in the inner two thirds of the annulus are incorporated into the end plates. Encased within the annular ring is the nucleus pulposus - a mucoid material of cartilage cells and irregularly arranged collagen fibers in a semifluid ground substance. It is this deformable, incompressible soft-tissue structure, separating two vertebral bodies, and contained by tightly packed collagen lamellae of the annulus, that allows one vertebral body to rock on the other during spinal movements without sacrificing stability, strength or weight-transferring capacity (34).

\section{Biochemical Structure}

The deformability of the nucleus pulposus is essential to the load-bearing function of the disc. Biochemically this property is linked to the hydration of the disc. Healthy discs are capable of imbibing enormous quantities of water and swelling to $>200 \%$ in volume $(35,36)$. Interference with the delicate homeostasis of nuclear matrix, such as lowering of matrix $\mathrm{pH}$ (37), triggers a cascade of biochemical reactions, leading to loss of water-binding capability of the disc and, ultimately, its capacity to attenuate loads.

The water-holding capability of the disc is determined by the status of its aggregating proteoglycans. Proteoglycans are macromolecular structures consisting of several molecules of mucopolysaccharides attached to a polypeptide chain (core protein). Proteoglycans exist as proteoglycan units and proteoglycan aggregates. The latter consist of many proteoglycan units attached to a hyaluronic acid chain by a link protein that is antigenic (33). Proteoglycans aggregates have the capacity to attract and retain large quantities of water depending on their mucopolysaccharide/glycosaminoglycan constituents. The human disc contains three different mucopolysaccharide/ glycosaminoglycan's ie, chondroitin sulfate, keratan sulfate and hyaluronic acid (38). Chondroitin sulfate holds twice as much water as keratan sulfate. Aging dehydrated discs have a higher ratio of keratan sulfate to chondroitin sulfate, and a decreased propensity to hold water and swell. The nucleus pulposus is $90 \%$ water at birth; this decreases to $70 \%$ at the age of 60 . This large volume of water endows the nucleus with its fluid properties; the proteoglycans and collagen fibrils that are the next major component account for its viscosity. The proteoglycan aggregates that constitute $25 \%$ of proteoglycans are held together in the nuclear matrix by Type II collagen fibrils.

Biochemically the nucleus and annulus have the same components, ie, water, collagen, and proteoglycans. The difference between the two is in the relative concentration of the components and the type of collagen that predominates in each part (39). Both type I and II collagen are found in the annulus but type I predominates, its concentration being higher in the outer annulus. Water makes up $60 \%$ to $70 \%$ of the weight in the annulus and is held in the domains of proteoglycan aggregates. The latter fill the spaces between the collagen lamellae, serving to bind the lamellae and preventing the annulus from buckling or fraying. As long as the lamellae remain healthy and intact and are held together by proteoglycan gel, the annulus will resist buckling and will sustain weight.

A continuous turnover of proteoglycans and collagen occurs in the disc, indicating that the disc is metabolically active. Chondrocytes and fibroblasts located in the end plates and interspersed among the collagen lamellae synthesize collagen and proteoglycans. They also produce degradative enzymes such as metalloproteinases, collagenases and stromelysin that are responsible for breakdown and removal of old collagen and proteoglycans. The activity of these enzymes is controlled by tissue activators and inhibitors.

\section{Nutrition}

The disc is essentially avascular and is nourished principally by diffusion from capillary plexuses beneath the vertebral end plates and those in the outer annulus. Uncharged ions such as glucose and oxygen, and positively charged ions permeate easily into the matrix. A high concentration of negatively charged carboxyl and sulfate ions in the proteoglycan matrix resists movement of negatively charged sulfate and chloride radicals into the nucleus (34). 
Another mechanism of nutrient supply is motion; loss of water with disc compression increases the electrolyte content of the disc, which then exerts an osmotic force and prevents further movement of water out of the disc. Release of compression allows the disc to rapidly regain height and volume as water is osmotically drawn into the disc (40). This flux of water is capable of carrying nutrients with it, as suggested by experiments on the canine disc, where long, vigorous spinal motion is shown to result in an efficient solute and metabolite transport and decrease in the lactate concentration, indicating stimulation of the aerobic metabolism in the disc (41). If a similar mechanism is presumed to operate in the human spine, vigorous exercise training on a regular basis can be expected to benefit disc nutrition. Similarly, limiting bed rest in low back pain subjects will serve to minimize the adverse effects of immobility on disc nutrition.

\section{Innervation}

Numerous studies attest to the rich innervation of the disc; even then the potential of the annulus to incite pain independently is not uniformly accepted and often viewed with skepticism. It has been well established that only the outer /mid third of the annulus is richly innervated; the inner third of the annulus and the nucleus are normally devoid of nerve fibers $(19,42,43)$.

A continuous interlacing network of nerve fibers made of ventral plexus (from the nerve plexus of the anterior longitudinal ligament) and dorsal plexus (by the nerve plexus of the posterior longitudinal ligament) surrounds the disc. These two plexuses interconnect at the level of the intervertebral foramen and supply nerve fibers to the annulus that are distributed laterally $>$ posteriorly $>$ anteriorly. The nerves supplying the dorsal surface are distinct from those supplying the ventral or lateral surface. The ventral surface of the disc receives fibers from the sympathetic trunk, its rami communicantes and the perivascular nerve plexus of segmental arteries. Direct branches from the ventral primary rami enter the posterolateral surface of the disc. Posteriorly the disc is innervated by the sinuvertebral nerves that contribute branches to the dorsal nerve plexus. The lumbar sinuvertebral nerve is a mixed nerve formed by a somatic root from the recurrent branch of the ventral ramus and an autonomic root from a gray ramus communicantes. Each lumbar sinuvertebral nerve supplies the disc at its level of entry into the vertebral canal and the disc above and below $(42,44)$. Whether the plexus of nerve fibers surrounding the intervertebral foramen has a sympathetic function or simply uses the rami communicantes for returning somatic afferent fibers from the disc to the ventral rami is not apparent. Most of the nerve fibers are sensory $(45,46)$ and involved in nociception, as suggested by isolation of substance $P$ from the free and complex nerve endings existing in the outer third of the annulus. The surface of the annulus has both encapsulated and unencapsulated receptors $(43,47,48)$. It is likely that the encapsulated nerve endings are proprioceptive, but there is no study to support this contention.

Quite often patients with lower lumbar disc lesions experience inguinal pain corresponding to L1-2 dermatomes. Retrograde axonal transport studies on rats have revealed an intriguing aspect of disc innervation whereby the anterior surface of the L5-6 disc receives nerve fibers from the L1 or L2 spinal nerves (49). Can a similar pattern of innervation to the lower lumbar discs in humans explain the inguinal pain reported by some patients with low back pain?

Mechanical factors are important in the genesis of discmediated pain; the mechanical properties of the disc are interlinked to its physicochemical status.

\section{Biomechanics}

The evolution of bipedal posture and ambulation in humans has transformed the horizontal vertebral column of vertebrates into a load-bearing erect spine that is required to efficiently transfer weight, provide stability and permit motion. This subjects the spine to compressive and torsional loads as the trunk flexes, extends, bends laterally and rotates axially on the pelvis. The stresses experienced are compressive, tensile, shear or a combination of these. Experimental work and biomechanical studies have identified compression and torsional forces as damaging to the spine, specifically to the disc, which bears the major brunt $(50,51)$. If the primary sources of disc pathology are these forces/stresses acting on the spine, why did the spine not evolve into a more rigid structure? What is the purpose of having a vertebral column capable of torsion and compression, unless it is somehow linked to the demands of human gait? Conventional wisdom will have us believe that the trunk is passive and the legs rotate the pelvis during ambulation. A revolutionary but thought-provoking concept is to consider the spine as the engine that powers human locomotion. Gracovetsky (52) has proposed the theory of the "spinal-engine' and regards the lumbar spine as the prime mover, the legs serving to amplify the movement. A lateral bend in the spine induces an axial torque that drives the pelvis to rotate. If this is true, the disc, which is the interbody joint, surely must be exposed to 
unusually high stresses/demands of everyday living. Is the disc then optimized to resist all kinds of loads efficiently or only certain loads and not others? What happens to a disc when it is compressed, bent or rotated?

The disc is designed to resist compressive loads effectively. A negative consequence of this specialization is the inability to resist torsional and other loads in an equally optimal manner (53). Biomechanical studies on isolated functional spinal units (vertebral body-disc-vertebral body) reveal that high-magnitude axial compressive loads that damage the endplates and the vertebral body are easily sustained by the disc (54). Central axial compression loading, as occurs with standing or sitting, exerts complex compressive and tensile stresses on the annulus (55) and increases intranuclear pressures (56). The inner annulus, in contrast to the outer annulus, experiences large-amplitude compressive and tensile stresses. The intranuclear pressures, which are uniformly distributed in the vertical and horizontal direction, increase as the loading increases (57). Elevated fluid pressures centrifugally deflect the endplates and support the inner laminae of the annulus, which bulges only slightly. There is thus an efficient transfer of compressive load from one vertebral endplate to the next by the nucleus pulposus and annulus fibrosus.

Axial rotation causes tensile/torsional loading of the disc. Most disc injuries result from torsional stresses (51), as their structure is not designed to handle torsional loads as well as compressive loads. Tensile stresses are nonuniformly distributed through the disc; the anterior and posterior regions of the disc are stronger than its central region (54) and the annulus is three times stronger in the direction of its fibers than in the horizontal direction (58). As a result, perpendicularly oriented normal stresses are easily absorbed by the alternating layers of annular fibers, while the shear stresses parallel to the disc surface are not resisted as well. These stresses are concentrated more at the periphery than at the center of the disc, stressing the annular fibers.

There is experimental evidence that, when a disc is bent, as occurs with spinal flexion, the nucleus is displaced posteriorly; extension causes the nucleus to move in the opposite direction (59). Clinically it is well known that endrange lumbar spine movements can centralize (cause pain to recede towards the lumbar spine) or peripheralize (cause pain to spread in radicular pattern) discogenic pain (60). Centralization of pain commonly occurs with lumbar extension. This principle is employed in designing exercises that treat discogenic pain and attempt to direct the dis- placed nuclear contents centrally into the disc.

Combined axial loading and lateral bending of spinal units result in maximum disc bulge posterolaterally. This tendency of the disc to herniate posterolaterally is not an inherent property of the disc but is related to the loading conditions (57). When a disc fails clinically, as occurs with annular disruption, it does so from a combination of compression, bending, torsion, and tension (53).

How does the structure of the intervertebral disc relate to its biomechanical characteristics - is the disc a solid or a fluid structure? The viscoelastic properties of the disc enable it to behave both as solid or liquid, depending on the rate and amplitude of spinal loading. At low compressive loads, just like fluids, it is flexible and offers little resistance. The same disc stiffens up as a solid in response to high loads and with increasing speed, thereby increasing stability $(53,61)$. There is very slight and slow deformation to loading in a healthy disc, unlike a degenerate disc that has abnormal creep characteristics and will deform earlier and at lower load values $(57,62)$. The human disc has low fatigue tolerance (63), making it susceptible to injury from repetitive loading or high-amplitude loads. What makes the disc viscoelastic? Viscoelasticity is a function of disc hydration; discs that retain fluid are stiffer than those that do not retain fluid (64). This property enables the disc to endure large-magnitude stresses in dynamic and static loading. It is little wonder that a normal disc can easily sustain forces two to three times the body weight (65).

As the disc degenerates, it undergoes structural and biochemical changes that irreversibly alter its biomechanical properties $(66,67)$. Degenerative changes first appear in men in the second decade and in women a decade later. By the time an individual reaches the age of 50,97\% of his/her lumbar discs are degenerated; most commonly involved discs are L3-4, L4-5 and L5-S1 segments $(66,68)$. A degenerated disc is less viscoelastic, ie, it can no longer attenuate shocks and distribute loads uniformly across the end plate. It deforms easily and at lower load values. There is a failure to generate higher compressive and tensile stresses at the inner annulus (55), resulting in inadequate intradiscal pressures. Intradiscal pressures generated with axial loading vary with loading condition, posture and state of disc hydration $(56,69)$. A correlation exists between intradiscal pressures and the degree of disc degeneration (70); severely degenerated discs manifest loss of pressurization (65). Loss of intradiscal pressure will result in less pressure at the center of the end plates and distribution of the load more around the periphery $(65,71)$. This aberrancy in 
the load-transferring mechanism is accompanied by pronounced internal and external deformations of the disc (65, 71). There is an increased outward bulging of the disc and an inward displacement of the annulus toward the center of the disc (59). It is likely that this abnormal anteroposterior annular stretch contributes to lamellar disruption and annular tears typical of internal disc disruption (66).

\section{PATHOLOGY}

Is an annular tear always painful? Some annular fissures will evoke pain, yet others may not cause any pain. What causes an annular fissure in one disc to be painful and in another to be painless? Vanharantta correlated pain to extension of radial annular fissures into the innervated outer third of the annulus (72); inner to mid annulus radial tears are not painful, as this part of the disc normally has no nerve supply. A combination of mechanical and chemical factors makes these rents painful. Physiologic loading of a healthy disc does not normally stimulate nociceptive nerve endings in the outer annulus. In a disc with fissures extending into the outer annulus and disrupting most of the lamellae, even minor physiologic stresses can mechanically stimulate nociceptors. While in a disc with an intact annulus, the load is uniformly distributed and shared equally by the lamellae constituting the annulus; in a disrupted disc the same load is absorbed by the few lamellae that are still intact, causing them to experience unusually high stresses (66). Ultimately the threshold for mechanical nociception is attained; this threshold for mechanical stimulation is attained earlier with chemical sensitization of the nerve endings. Furthermore, centripetal growth of nerve fibers along radial tears into the inner annulus provides a morphologic substrate for true discogenic pain $(45,73)$. Some of these nerve fibrils express growth-associated protein 43 - a protein expressed during axonogenesis, supporting the theory of nerve ingrowth. Morphologically these nerve endings are nociceptive and express substance $\mathrm{P}$, a nociceptor. Absence of neural structures in control discs and existence in painful discs implicate them in the pathogenesis of chronic back pain.

Chemical sensitization of nerve endings occurs with release of nociceptive substances by the disc $(74,75)$. Normally the cellular synthetic capability of a disc can effectively inhibit activation of degradative enzymes. Impaired cellular function accompanies changes in nuclear $\mathrm{pH}$ and release of prostaglandin $\mathrm{E}$, histamine-like substances, potassium ions, lactic acid, polypeptide amines and phospholipase $A_{2}(76,77)$. These chemicals may play a role in the initiation or maintenance of disc degeneration. Theo- retically interventions directed at inactivating inflammatory mediators can be potentially therapeutic. An example of direct application of basic science research into clinical practice has been the use of steroids to counter phospholipase $\mathrm{A}_{2}$ activity. Phospholipase $\mathrm{A}_{2}$ liberates arachidonic acid from cell membranes and is the limiting factor in the production of powerful inflammatory mediators, ie, prostaglandins and leukotrienes. It has a direct neurotoxic potential in addition to its potent inflammatory and edemaproducing properties (78). Phospholipase $\mathrm{A}_{2}$ is implicated in the genesis of pain in herniated discs - extraordinarily high Phospholipase $\mathrm{A}_{2}$ activity has been reported in herniated discs in comparison to other human tissues (79). The pain-generating capability may be related to direct excitation of annular nociceptors, nerve injury from enzymatic degradation of phospholipids, or secondary to nerve inflammation (74-78). It is speculated that leakage of nociceptors from the disc sensitizes the $\mathrm{C}$ or A delta unmyelinated nerve fibers in the annulus and the dorsal root ganglion, lowering the nociceptor threshold for mechanical stimulation $(74,80,81)$. Mechanical irritation of sensory nociceptive terminals in an incompetent disc then occurs, with physical loading in the physiologic range of the disc $(81,82)$.

What about the immunogenic potential of a human disc can the disc mount an autoimmune attack? The protein in nuclear proteoglycan aggregates is immunogenic. This is well documented in clinical and animal models $(29,33,83$, 84). Nonetheless, annular fissures do not have the same potential as herniated nucleus pulposus to generate an immunologic response $(79,85,86)$. Studies comparing the immunocompetent cellular response in contained (painful annular fissures surgically excised) and herniated discs at the epidural interface do not support autoimmune mechanisms as pathogenetic in internal disc disruption.

An adequate supply of nutrients is essential for the structural and biochemical integrity of the disc. Almost $50 \%$ of nutrient requirements are met by diffusion across the cartilaginous endplates. Compression injury of the vertebral end plates interferes with disc nutrition and is followed by an inflammatory biochemical degradation of the disc matrix (34). Experimental work links matrix degeneration to endplate separation. The biochemical cascade, which eventually culminates into nuclear disintegration and annular disruption, is triggered by activation of metalloproteinase and interleukins in the disc matrix (87). Metalloproteinases are enzymes that decompose the link protein in proteoglycan aggregates; MMP-3 is a matrix metalloproteinase isolated from disc cells (88). When activated, it decomposes aggre- 
gating proteoglycans and depletes the disc matrix of its water content. Normally tissue inhibitor of metalloproteinase binds and inactivates MMP-3. Degenerated discs produce interleukins, IL-1 and IL-6; IL-6 inhibits tissue inhibitor of metalloproteinase generation and IL1 enhances production of MMP-3. Studies on surgically removed human discs indicate an imbalance between MMP-3 and tissue inhibitor of metalloproteinase, with a higher ratio of cells positive for MMP-3 (89). This dysequilibrium is speculated to enhance matrix destruction and consequently disc dehydration. It is likely that MMP-3 also has a role in degeneration of cartilaginous endplates; MMP-3 staining in the endplates correlates with osteophyte formation.

Radial annular tears provide a route for inflammogenic nuclear fluid to leak out into the epidural space and bathe the dural sac and exiting nerve roots $(80,81)$. This mechanism is speculated to cause some patients to present clinically with features suggestive of a prolapsed disc but no imaging evidence of one. A clinically relevant disc herniation, however, does not occur in the absence of endplate separation and matrix degeneration. Experimentally nuclear extrusion cannot be induced through surgically created annular cuts despite axial loads of 1000 N (90). Probably the fibrous structure of the nucleus, endplate fibrous attachments and self-sealing property of the annulus inhibit such displacements.

\section{CLINICAL PRESENTATION}

At what point in the pathogenesis degenerative disc disease manifests clinically as internal disc disruption is not obvious. Internal disc disruption is a common entity; nearly $30 \%$ to $50 \%$ of subjects with chronic low back pain have internal disc disruption (9). A clinical diagnosis of internal disc disruption based on history and physical examination alone is extremely difficult. Most of the patients experience diffuse, dull ache or a deep-seated, burning, lancinating pain in the back. Some will complain of a sensation of a weak, unstable back. Referral of pain into the hips and lower limbs is not uncommon. Almost all of these patients have a varying degree of sitting intolerance. The movements involving the lumbar spine are slow, guarded and restricted. In acute cases a history of lifting trauma precedes the back pain. In the chronic stage pain and muscle spasm are less dramatic and more nondescript. Typically there is no objective evidence of radiculopathy, even in those who have a radicular pattern of pain referral. Often these patients will be labeled as being functional or as malingerers due to the vague symptoms and lack of objec- tive data. In general, nondescript pain and a negative physical examination in a severely apprehensive patient is the most common clinical scenario. Moreover, there is no constellation of symptoms and signs that can reliably distinguish the internal disc disruption population of patients from those without discogenic pain (9).

A prospective, blinded study (91) employed McKenzie endrange lumbar test movements to differentiate discogenic from non discogenic pain. This study compared discographic pain provocation and annular competency to the presence or absence of centralizing, peripheralizing or abolishing low back and radicular pain with McKenzie exercises. Discogenic pain was present in $69 \%$ of peripheralizers and $74 \%$ of centralizers. The annulus was functionally competent in those who centralized pain; outer annular disruption was more likely in those who peripheralized pain.

\section{DIAGNOSTICIMAGING}

While physical examination alone remains insufficient to establish a diagnosis of internal disc disruption, modern diagnostic imaging has immensely contributed to advancing our understanding of internal disc disruption.

Plain X-Rays: Routine lumbar spine X-rays are usually negative. Subtle findings in chronic long-standing cases include mild narrowing of the disc space; flexion-extension stress views may reveal excessive excursion of one vertebral body on the adjacent one at the involved disc level $(92,93)$.

\section{Computerized Tomograms}

Computerized tomography scan of lumbar spine and myelograms are essentially normal $(14,92)$. Low-density zones in the annular region of the intervertebral disc seen on high-quality routine CT scans of the lumbar disc may suggest annular pathology.

\section{Magnetic Resonance Imaging of Lumbosacral Spine}

Magnetic resonance imaging delineates internal disc morphology and disc hydration $(67,94)$. The MRI signal intensity is proportional to the water content of the proteoglycan matrix of the disc. Well-hydrated discs have a high signal intensity (bright white) in contrast to degenerated discs that disclose signal reduction on T2-weighted sequences $(94,95)$. Usually, normal disc signal intensity suggests a normal disc and loss of signal intensity on MRI 
correlates with abnormal disc morphology on discography $(96,97)$; however, case reports indicate that a normal MRI signal does not rule out internal disc disruption $(98,99)$. Likewise, abnormal disc signal intensity cannot reliably distinguish a painful disc from an asymptomatic degenerated disc $(100,101)$.

Sometimes, on T2-weighted sagittal images, a high-intensity zone is visualized in the posterior annulus of the disc, as a focal high-intensity (bright white) signal distinct from the signal of the nucleus pulposus (102). Its presence is shown to correlate significantly with the existence of grade 4 symptomatic annular disruption (103). Seen in $28 \%$ of subjects with idiopathic low back pain, the high-intensity zone has low sensitivity but a high specificity, the positive predictive value for a symptomatic disc disruption being $86 \%$ (102). The bright signal of high intensity zone on T2weighted sequences most likely represents inflammation, neovascularization or invasion by granulation tissue (104, 105).

\section{Lumbar Discogram/Postdiscography computerized to- mography}

Definitive diagnosis relies on provocation discography to reproduce pain and CT discogram to reveal grade 3 radial fissures (106-108). According to the guidelines laid down by the International Society for the Study of Pain, it is essential that disc stimulation reproduce the patient's pain, provided, as a control, stimulation of at least one and preferably two other discs fails to reproduce pain (109). In this manner false-positive responses to disc stimulation are eliminated.

Discography is a physiologic test that explicitly determines whether a degenerative disc is painful. The key feature of discography is the patient's response to disc stimulation, not the appearance of the disc. This procedure is not painful in asymptomatic individuals even with degenerative discs but is frequently painful in patients with low back pain. When the guidelines are rigidly applied, discography is a powerful tool in diagnosing discogenic low back pain, as it provides information that cannot be obtained by other methods (110-113).

The guidelines were outlined in the "1988 Position Statement on Discography" and subsequently reaffirmed by the Executive Committee of the North American Spine Society $(114,115)$. It states, "Discography is indicated in the evaluation of patients with unremitting spinal pain, with or without extremity pain, of greater than 4 months' duration, when the pain has been unresponsive to all appropriate methods of conservative therapy. Before discography patients should have undergone investigations with other modalities which have failed to explain the source of pain; such modalities should include, but not be limited to, CT scanning, MRI scanning and/ or myelography. In these circumstances, discography followed by CT scanning will permit precise description of the internal anatomy of a disc and a detailed determination of the integrity of the disc substructures. Additionally, the anatomic observations may be complemented by the critical physiologic induction of pain which is recognized by the patient as similar to or identical with his or her clinical complaints. By including multiple levels in the study the patient acts as his/her own control for evaluating the reliability of pain response."

The information compiled on discography includes (1) volume of contrast injected; (2) pattern of contrast distribution (fissuring, bilobed, unilobed, extravasation, annular pattern); (3) amount of resistance to the injection; (4) pain response (most important part of the procedure)-no pain, pressure, discordant pain or concordant pain, nature and location; (5) and CT discogram to help define pathology, including any lateral disc herniation and annular fissuring $(108,116)$.

Dallas discogram classification relates these five separate categories of information to provide a comprehensive, quantitative, scaled classification system for disc pathology (116). Anteroposterior, lateral radiographic views and axial view seen by postdiscogram CT are evaluated for escape of contrast. Annular disruption is graded from " 0 " to " 3 ", with " 0 " indicating no annular disruption; " 1 " indicating radial fissuring into inner annulus; " 2 " extension of radial fissure into outer annulus; and " 3 " escape of contrast from radial into circumferential fissure. Aprill and Bogduk (102) have described four grades of annular fissure. Grade 3 reaches the outer third of annulus fibrosus; grade 4 fissure spreads additionally circumferentially within the annulus by an arc of at least 30 degrees.

A strong correlation exists between extent of annular disruption and reproduction of pain response on provocation discography (112). Fissures restricted to the inner third of the annulus are rarely painful, while $>70 \%$ of fissures reaching the outer third of the annulus are painful and, reciprocally, over $70 \%$ of painful discs have third-degree fissures (72, 112, 116). Provocation discography is highly specific, as it is not painful in normal volunteers (24). Reproduction of pain on discography is indicative of a clinically significant abnormality of that disc. 
Limitations of this procedure are its invasive nature, significant radiation, and potential complications. The potential for complications, even though low in trained hands, should nevertheless be factored into the decision process and all necessary precautions instituted. The reported complications include discitis, $0.1 \%$ to $0.2 \%$; nerve irritation; subarachnoid puncture; chemical meningitis; exacerbation of pain; and allergic reaction to contrast (117-119).

\section{TREATMENT}

The concept of the disc's becoming not only dynamically incompetent but biochemically active after injury is novel and not easily acceptable. Our thought process is often trapped into viewing the disc as capable of manifesting pain only as a space-occupying lesion. Consequently, ideal treatment for internal disc disruption is yet to evolve. Current approaches include nonoperative conservative and surgical options.

\section{Conservative Nonsurgical Treatment}

This includes pharmacologic pain control complementing a specific program of lumbar exercises and image-guided, minimally invasive interventional procedures on the disc (120).

Dynamic Lumbar Stabilization vs McKenzie Exercise Program: Low back pain limits daily activities, curtails ability to work and causes a deterioration in quality of life (121). The goal of treatment is to improve function and quality of life; treat pain; and, in the long term, prevent future back injury and disability. Preventive measures must be the mainstay of spine rehabilitation.

An adequate rehabilitation program will control pain to enable participation in an exercise program; instruct in proper body mechanics to facilitate pain-free movements; provide postural exercises and flexibility training; restore normal lumbopelvic rhythm and range of motion in the entire kinetic chain; initiate specific strengthening exercises for the lumbar spine; identify risk factors for lumbar spine injury and institute injury prevention measures; recommend aerobic conditioning and sport-specific or jobspecific training/hardening; and ultimately, return an individual to the same or a lower level of activity.

Establishing an accurate diagnosis and early intervention is essential. Preventive measures and instructions in proper body mechanics aim to avoid repetitive flexion and torsional stress, reduce translational stress, and balance shear forces to the intervertebral segments. These measures serve to eliminate microtrauma, encourage healing and al- ter the progress of the degenerative process. Adequate flexibility and spinal range of motion are prerequisites to strengthening exercises. Flexibility exercises must include those for the hamstrings, quadriceps, iliopsoas, gastrocsoleus, hip rotators, and iliotibial band. Diurnal variations in disc and ligament flexibility have been reported. Bending and lifting performed early in the morning when ligamentous and annular fibers are less extensible are more likely to cause fatigue damage to the disc than similar activities performed later in the day.

The two commonly employed exercise programs for low back pain are dynamic lumbar stabilization exercises and McKenzie exercises $(122,123)$. Results of conservative treatment are comparable to surgery in terms of pain relief, improving quality of life and return to work status on longterm follow-up. Successful outcome has been reported in $96 \%$ of patients with herniated nucleus pulposus and extruded discs with aggressive rehab using a lumbar stabilization program.

Dynamic lumbar stabilization training attempts to achieve control of lumbar lordosis in flexion and extension movements. Pelvic positioning is the key to postural control of the spine. A closely supervised program of exercise training focuses on obtaining adequate musculoligamentous control of the lumbar spine; improperly performed abdominal strengthening techniques are a frequent cause of lumbar spine injuries. A specific program for internal disc disruption is not described; the principles of rehabilitation are similar to that tried and proven for lumbar radiculopathy with herniated nucleus pulposus (122).

The lumbar stabilization program can be divided into basic-intermediate-and advanced-level exercises. At the basic level exercises are performed in the supine or prone position. This will progress to exercises in kneeling; standing; and, finally, to movements of position transition. Each exercise is designed to develop isolated cocontraction muscle patterns and stabilize the lumbar spine in its neutral position. A neutral spine position is not necessarily zerodegree lordosis but the most comfortable position for that individual. The patient learns to find and maintain his neutral spine position throughout the strengthening program. By strengthening the abdominal muscles, back extensors and pelvic stabilizers the spine is braced. A corset effect is created by contracting abdominal muscles in concert with the latissimus dorsi and pelvic stabilizers. The abdominal muscles by their attachment to the dorsolumbar fascia can flex and extend the lumbar spine and serve to eliminate shear stress on the lumbar intervertebral seg- 
ments. Spinal extensors reduce translational stress and balance shear stress to intervertebral segments during activity. Among the back extensors the short segmental multifidus is most active but is the most difficult muscle to strengthen. Lifting power of the lumbar spine is controlled by the gluteus. Strengthening exercises that strengthen the gluteus, quadriceps and hamstrings are included in the program. Careful repetition of these exercises facilitates engram motor programming. Once proper exercise form and technique have been achieved the program is advanced. Functional progress rather than the pain level is the criterion for determining advancement to more challenging exercises. The endpoint is maximal functional capacity that cannot be improved with additional exercise training or pain control (122).

McKenzie exercises for low back pain are effective against both acute and chronic low back pain. A series of individualized exercises localizes and ultimately eliminates the patient's pain. The subject's response to repeated lumbar movements such as flexion, extension, lateral bending and rotation is used to assess which movements reduce the patient's most peripheral symptoms. These movements are then combined into an individualized exercise regimen. By regularly performing these exercises, the patient learns to centralize and eliminate his or her symptoms. Exercises and movements that centralize the pain are encouraged and those that peripheralize the pain are avoided. The McKenzie method has been shown in a prospective, randomized clinical trial to be twice as effective as traction and back schools in alleviating pain: $98 \%$ of acute pain and $80 \%$ chronic pain had good outcome, with a return to work rate of $90 \%$ (123). Its proponents believe it results in faster recovery, less time off work, fewer treatments and fewer recurrences $(60,123)$. Some patient groups that do not respond to this mechanical approach are patients with extruded disc fragments, lumbar stenosis, and internal disc disruption. Secondary gain obviously hampers recovery. Inability to identify pain-centralizing movements in a patient with referred pain predicts disc extrusion or internal disc disruption identified by CT/discography (91).

Intradiscal Steroid Instillation: As the pain of internal disc disruption is chemically mediated, inhibiting chemical activation of nociceptors at the site of peripheral stimulation is logically appealing. Steroids have proved to be clinically beneficial in inhibiting Phospholipase $A_{2}$. Delivery of steroids into the disc, theoretically, should give longlasting pain relief by inhibiting Phospholipase $\mathrm{A}_{2}$ activation and thereby reducing neuronal hypersensitization. In practice intradiscal steroids have given favorable but not dramatic results. There are not many controlled, prospective trials to determine its efficacy. Feffer used hydrocortisone and noted on a retrospective, nonblinded study an initial improvement rate of $67 \%$ and an overall remission rate of $46 \%$ (124). The results in uncontrolled studies are mixed with $50 \%$ improvement at 1 month and $33 \%$ at 3 months (125). A small, prospective, double-blind trial found no statistically significant benefit from use of intradiscal steroids (126). This study was limited by the small sample size, lack of a true placebo control and a short 2-week follow-up.

Radiofrequency Denervation: Radiofrequency lesioning of the gray rami communicans has been employed to treat discogenic pain. Symptomatic discs are identified on discography and the rami communicans are lesioned above and below the painful disc, at a level that corresponds to the junction of the upper two thirds with the lower third of the vertebral body. Complete denervation of the disc annulus is a desirable goal, but not achievable in the absence of available technique for radiofrequency lesioning of the sinuvertebral nerve. Approximately 50\% report excellent results in terms of pain reduction. Although this technique effectively treats pain from the anterolateral aspect of the disc, it does not alleviate pain from the posteromedial region of the disc, where most of the pathology resides. Failure to denervate the posteromedial part of the disc thus limits the utility of this procedure $(127,128)$.

\section{Intradiscal Electrothermal (IDET) Therapy}

A new technique employed to treat disc-mediated pain is intradiscal electrothermal coagulation. The underlying principle is thermal shrinkage and remodeling of collagen after exposure to specific temperature ranges. Thermomodulation of collagen has been effective in promoting capsular stability in recurrent shoulder dislocations. It is believed that a similar mechanism in the disc will achieve nuclear shrinkage, seal annular fissures and thermocoagulate annular nociceptors. Studies on human cadaveric disc and animal model document the feasibility of this procedure (129). A semi-rigid catheter is navigated into the disc through a 17-gauge introducer needle and positioned within the nucleus adjacent to the posterior annular wall at the 4 to 8 o'clock zone. The access to the disc is extrapedicular from the side opposite to the side of the annular tear. In some cases a bilateral approach is indicated. A thermal resistive coil then generates heat at the active tip, starting at $65^{\circ} \mathrm{C}$ and increasing incrementally to 80 to $90^{\circ} \mathrm{C}$ over a duration of 14 minutes. The initial results are promising, with $80 \%$ of patients reporting suc- 
cessful outcome (129) . Controlled clinical trials are needed to identify the patient population and determine the limitations and efficacy of this treatment modality.

\section{Surgical Management}

Crock first described anterior lumbar interbody fusion for internal disc disruption. He reported a union rate of $96 \%$ and a high return-to-work rate $(130,131)$. Several authors since then have reported variable results with this procedure (132-138). Overall success ranges between $46 \%$ and $86 \%$. Outcome-assessment measures include pain relief, fusion rate, return-to-work status and postoperative complications. Good pain relief is reported by $60 \%$ to $75 \%$ of patients. Successful fusion increases the likelihood of a better outcome as shown by Flynn and Hoque (139), when 15 of 26 patients with good clinical results also had a solid fusion. The reported rate of solid fusion is in the range of $48 \%$ to $94 \%$. The success rate in single-level fusions is $85 \%$ to $89 \%$. As the number of levels fused increases, chances of achieving a solid arthrodesis progressively diminishes. Twenty-five percent may need reoperation (136). Return-to-work rate is $68 \%$ and the average time taken is 6 months. Common postoperative complications are retrograde ejaculation, graft extrusion and pseudoarthrosis (132138).

Surgical decision making involves identifying the painful disc; and determining the number of levels to fuse, the surgical approach, ie, anterior interbody only or combined anteroposterior fusion; and the necessity for instrumentation. Some surgeons select candidates for anterior lumbar interbody fusion based on a positive discogram in the setting of chronic persistent, disabling low back pain that is unresponsive to 1 year or longer of conservative treatment (135). When anterior lumbar interbody fusion is not feasible, posterior translaminar fusion is attempted to obtain segmental immobilization (134).

Two definite disadvantages of surgical fusion are the failure to maintain disc height and loss of segmental motion at the fused levels, which contribute to cephalocaudad neuroforaminal stenosis and overloading of adjacent disc levels. Recent developments in lumbar spine surgery attempt to preserve disc height by interposing titanium cages in the disc space. Another innovative technique involves interposing articulating intervertebral disc prostheses that are designed to restore disc height and segmental function (140-142). There are over 1,000 cases of intervertebral endoprosthesis reported in the European literature. Although the idea is appealing and physiologically sound, there are valid concerns pertaining to biocompatibility, long-term structural integrity and function. This procedure has not been approved by the Food and Drug Administration for use in the United States.

\section{CONCLUSION}

The fact that chronic low back pain is considered a social epidemic and a tremendous economic drain (28) has fueled the widely popularized concept of minimizing or denying medical assistance to low back pain subjects who demonstrate no evidence of an underlying potentially devastating cause of low back pain. Based on this philosophy has come the adage, "Learn to live with it." However, this policy of active nonintervention has not minimized the disability of low back pain, instead it perpetuates the very problems we desire to avoid. Low back pain is as enigmatic as ever, it continues to mock and challenge our clinical acumen. We need to recognize that low back pain is a symptom complex with diverse etiologies. Some of these will be amenable to treatment and some will defy any attempts to provide lasting relief. A logical approach is to identify treatable causes of low back pain in subjects who continue to be disabled by it beyond the 6- to 8-week period of natural recovery. Internal disc disruption is a common cause of disabling low back pain in a substantial number of young, healthy adults. It is possible that early recognition and aggressive treatment of internal disc disruption may be a step towards aborting the process of chemical sensitization of nociceptive nerve endings and thereby avoiding perpetuation of chronic pain in this subgroup.

\section{REFERENCES}

1. Cypress BK. Characteristics of physician visits for back symptoms. A national perspective. Am J Public Health 1983; 73: 389-395.

2. Kelsey JL, Golden AL. Occupational and workplace factors associated with low back pain. Spine. State Art Rev 1987; 2: 61-73.

3. White AA III, Gordon SL. Synopsis. Workshop on idiopathic low-back pain. Spine 1982; 7:141-149.

4. Workers Compensation Back Claim Study. Boca Raton, Florida. National Council on Compensation Insurance, 1993; pp 1-25.

5. Deyo RA, Tsui-Wu JY. Descriptive epidemiology of low-back pain and its related medical care in the United States. Spine 1987; 12: 264-268.

6. Mooney V. Where is the pain coming from? Spine 1987; 12: 754-759.

7. Nachemson AL. The lumbar spine. An orthopaedic challenge. Spine 1976; 1: 59-71.

8. Deyo RA, Rainville J, Kent DL. What can the history and physical examination tell us about low back pain? 
JAMA 1992; 268: 760-765.

9. Schwarzer AC, Aprill CN, Derby R et al. The prevalence and clinical features of internal disc disruption in patients with chronic low back pain. Spine 1995; 20: 1878-1883.

10. Bogduk N, Modic MT. Controversy. Lumbar discography. Spine 1996; 21: 402-404.

11. Dandy WE. Concealed ruptured intervertebral disks. A plea for the elimination of contrast mediums in diagnosis. JAMA 1941; 117: 821-823.

12. Hirsch C. An attempt to diagnose the level of a disc lesion clinically by disc puncture. Acta Orthop Scand 1948; 18: 131-140.

13. Lindblom K. Diagnostic puncture of the intervertebral discs in sciatica. Acta Orthop Scand 1948; 17: 231239.

14. Crock HV. A reappraisal of intervertebral disc lesions. Med J Aust 1970; 1: 983-989.

15. Mixter WJ, Barr JS. Ruptures of the intervertebral disc with involvement of the spinal canal. $N$ Engl $J$ Med 1934; 211: 210-215.

16. Ghormley RK. Low back pain with special reference to the articular facets with presentation of an operative procedure. JAMA 1933; 10: 1773-1777.

17. Fernstrom U. A discographical study of ruptured lumbar intervertebral discs. An investigation based on anatomical, pathological, surgical and clinical studies and on experiments in provocation of pain with special reference to simple ruptured lumbar discs and to discogenic pain. Acta Chirurgica Scandinavica 1960; 258: $1-60$

18. Smythe J, Wright V. Sciatica and the intervertebral disc. J Bone Joint Surg 1958; 40-A: 1401.

19. Roofe PG. Innervation of the annulus fibrosus and posterior longitudinal ligament. Arch Neurol Psychiatry 1940; 44: 100-103.

20. Vanharanta H, Sach BL, Ohnmeiss DD et al. Pain provocation and disc deterioration by age. A CT/ discographic study in a low back pain population. Spine 1989; 14: 420-423.

21. Lindblom K. Protrusions of the discs and nerve compression in the lumbar region. Acta Radiol Scand 1944; 25: 195-212.

22. Holt EP Jr. The question of lumbar discography. $J$ Bone Joint Surg 1968; 50A: 720-726.

23. Simmons JW, Aprill CN, Dwyer AP et al. A reassessment of Holt's data on "The question of lumbar discography." Clinical Orthopedics Related Research 1988; 237: 120-124.

24. Walsh T, Weinstein J, Spratt K et al. Lumbar discography in normal subjects. A controlled prospective study. J Bone Joint Surg 1990; 72A: 1081-1088.

25. Jensen MC, Brant-Zawadzki MN, Obuchowski N et al. Magnetic resonance imaging of the lumbar spine in people without back pain. N Engl J Med 1994; 331: 69-73.
26. Powell MC, Wilson M, Szypryt P et al. Prevalence of lumbar disc degeneration observed by magnetic resonance in symptomless women. Preliminary communication. Lancet 1986; 2: 1366-1367.

27. Wiesel SW, Tsuormas N, Feffer HL et al. A study of computer assisted tomography. I. The incidence of positive CAT scans in an asymptomatic group of patients. Spine 1984; 9: 549-551.

28. Deyo RA. Editorial comment. Magnetic resonance imaging of the lumbar spine: Terrific test or tar baby? N Engl J Med 1994; 331: 115-116.

29. Bobechko WP, Hirsch C. Auto-immune response to nucleus pulposus in the rabbit. J Bone Joint Surg 1965; 47B: 574-580.

30. Gertzbein SD, Tile M, Gross A et al. Autoimmunity in degenerative disc disease of the lumbar spine. Orthop Clin North Am 1975; 6: 67-73.

31. Gertzbein SD. Degenerative disc disease of the lumbar spine. Immunological implications. Clin Orthop 1977; 129:68-71.

32. Naylor A. The biophysical and biochemical aspects of intervertebral disc herniation and degeneration. Ann Roy Coll Surg Engl 1962; 31: 91-114.

33. Pankovich AM, Korngold L. A comparison of the antigen properties of nucleus pulposus and cartilage protein polysaccharide complexes. J Immunol 1967; 99:431-437.

34. Bogduk N. Clinical Anatomy of the Lumbar Spine. Edition 3. New York, Churchill-Livingstone 1997; pp 13-31.

35. Charnley J. The imbibition of fluid as a cause of herniation of the nucleus pulposus. Lancet 1952; 1: 124127.

36. Hendry NGC. The hydration of the nucleus pulposus and its relation to intervertebral disc derangement. $J$ Bone Joint Surg 1958; 40: 132-144.

37. Nachemson AL. Intradiscal measurements of $\mathrm{pH}$ in patients with lumbar rhizopathies. Acta Orthop Scand 1969; 40: 23-42.

38. DiFabio JL, Pearce RH, Caterson B et al. The heterogeneity of the non-aggregating proteoglycans of the human intervertebral disc. Biochem J 1987; 244: 27 33.

39. Brickley-Parsons D, Glimcher MJ. Is the chemistry of collagen in intervertebral discs an expression of Wolff's law? A study of the human lumbar spine. Spine 1984; 9: 148-163.

40. Kraemer J, Kolditz D, Gowin R. Water and electrolyte content of human intervertebral discs under variable load. Spine 1985; 10: 69-71.

41. Holm S, Nachemson A. Variations in the nutrition of the canine intervertebral disc induced by motion. Spine 1983; 8: 866-874.

42. Bogduk N, Tynan W, Wilson AS. The nerve supply to the human lumbar intervertebral discs. J Anat 1981; 132: $39-56$ 
43. Malinsky J. The ontogenetic development of nerve terminations in the intervertebral discs of man. Acta Anat 1959; 38: 96-113.

44. Groen GJ, Baljet B, Drukker J. Nerves and nerve plexuses of the human vertebral column. Am J Anat 1990; 188: 282-296.

45. Coppes ME, Marani E, Thomeer RTWM et al. Innervation of painful lumbar discs. Spine 1997; 22: 23422350.

46. Nakamura S, Takahashi K, Takahashi Y et al. Origin of nerves supplying the posterior portion of lumbar intervertebral discs in rats. Spine 1996; 21: 917-924.

47. Yamashita T, Minaki Y, Oota I et al. Mechanosensitive afferent units in the lumbar intervertebral disc and adjacent muscle. Spine 1993; 18: 2252-2256.

48. Yoshizawa H, O'Brien JP, Thomas Smith W et al. The neuropathology of intervertebral discs removed for low back pain. J Pathol 1980; 132: 95-104.

49. Morinaga T, Takahashi K, Yamagata M et al. Sensory innervation to the anterior portion of lumbar intervertebral disc. Spine 1996; 21: 1848-1851.

50. Farfan HF, Sullivan JD. The relation of facet orientation to intervertebral disc failure. Can J Surg 1967; 110: 179.

51. Farfan HF. Mechanical Disorders of the Low Back. Philadelpia, Lea \& Febiger, 1973; pp 199-211.

52. Gracovetsky S. Linking the spinal engine with the legs. A theory of human gait. In Vleeming A, Mooney V, Dorman T et al (eds). Movement Stability and Low Back Pain. The Essential Role of the Pelvis. New York, Churchill-Livingstone, pp 243-251, 1997.

53. White AA III, Panjabi MM. Clinical Biomechanics of the Spine. Edition 2. Philadelphia, Lippincott-Raven, 1990; pp 3-19.

54. Brown T, Hanson R, Yorra A. Some mechanical tests on the lumbosacral spine with particular reference to the intervertebral disc. J Bone Joint Surg 1957; 39A: 1135.

55. Shiraji-Adl SA, Shrivastava SC, Ahmed AM. Stress analysis of the lumbar disc body unit in compression. A 3 dimensional non-linear finite element study. Spine 1984; 9: 120.

56. Nachemson A, Morris J. Vivo measurements of intradiscal pressure. J Bone Joint Surg 1964; 46 A: $1077-$ 1092.

57. Adams MA, McMillan DW, Green TP. Sustained loading generates stress concentration in lumbar intervertebral discs. Spine 1996; 21: 434-438.

58. Galante JO. Tensile properties of the human lumber annulus fibrosus. Acta Orthop Scand (Suppl) 1967; 100: 1.

59. Krag MH, Serousi RE, Wilder DG et al. Internal displacement distribution from in-vitro loading of human thoracic and lumbar spinal motion segments. Experimental results and theoretical predictions. Spine 1987; 12: 1001 .
60. Dimaggio A, Mooney V. The McKenzie program. Exercise effective against back pain. J Musculoskel Med 1987; 4: 63-74.

61. Iatridis JC, Weidenbaum M, Setton LA et al. Is the nucleus pulposus a solid or a fluid? Mechanical behavior of the nucleus pulposus of the human intervertebral disc. Spine 1996; 21: 1174-1184.

62. Kazarian LE. Creep characteristics of the human spinal column. Orthop Clin North Am 1975; 6:3.

63. Virgin W. Experimental investigations into the physical properties of the intervertebral disc. J Bone Joint Surg 1951; 338: 607.

64. Andersson GBJ, Schultz AB. Effects of fluid injection on mechanical properties of intervertebral discs. $J$ Biomech 1979; 12: 453-458.

65. Nachemson AL. Disc pressure measurements. Spine 1981; 6: 93-97.

66. Adams MA, McNally DS, Dolan P. Stress distribution inside intervertebral discs. The effects of age and degeneration. J Bone Joint Surg 1996; 78: 965-972.

67. Panagiotacopulos ND, Pope MH, Block R et al. Water content in human intervertebral discs. Part I. Measurement by magnetic resonance imaging. Spine 1988; 13: 913.

68. Adams MA, Dolan P, Hutton WC. The stages of disc degeneration as revealed by discograms. J Bone Joint Surg 1986; 68: 36-41.

69. Quinell RC, Stockdale HR. Observations of pressure within normal discs in the lumbar spine. Spine 1983; 8:166.

70. Panjabi MM, Brown M, Lindahl S et al. Intrinsic disc pressure as a measurement of integrity of the lumbar spine. Spine 1988; 13: 913.

71. Reuber M, Schultz A, Denis F et al. Bulging of lumbar intervertebral discs. J Biomech Eng 1982; 104: 187.

72. Vanharanta H, Guyer RD, Ohnmeiss DD et al. Disc deterioration in low-back syndromes. A prospective, multi-center CT/Discography study. Spine 1988; 13: 1349-1351.

73. Freemont AJ, Peacock TE, Goupille P et al. Nerve ingrowth into diseased intervertebral disc in chronic back pain. Lancet 1997; 350: 178-181.

74. McCarron RF, Wimpee MW, HudkinsPG et al. The inflammatory effect of nucleus pulposus. A possible element in the pathogenesis of low back pain. Spine 1987; 12: 760-764.

75. Nygaard O P, Mellgren S I, Osterud B. The inflammatory properties of contained and noncontained lumbar disc herniation. Spine 1997; 22: 2484-2488.

76. O'Donnell JL, O'Donnell AL, Prostaglandin E Content in herniated lumbar disc disease. Spine 1996; 21: 1653-56.

77. Franson RC, Saal JS, Saal JA. Human disc phospholipase $A_{2}$ is inflammatory. Spine 1992; 17: 129-132.

78. Saal JS, Franson R, Myers R et al. Human disc PLA2 induces neural injury. A histomorphometric study. 
From proceedings of the annual meeting. International Society for the Study of the Lumbar Spine, Chicago, 1992.

79. Saal JS, Franson RC, Dobrow R et al. High levels of inflammatory phospholipase $\mathrm{A}_{2}$ activity in lumbar disc herniations. Spine 1990; 15: 674-678.

80. MacMillan J, Schaffer JL, Kambin P. Routes and incidence of communication of lumbar discs with surrounding neural structures. Spine 1991; 16: 167-71.

81. Weinstein JN. Mechanism of spinal pain. The dorsal root ganglion and its role as a mediator of low back pain. Spine 1986; 11; 999-1001.

82. Howe JF, Loesser JD, Calvin WH. Mechanosensitivity of dorsal root ganglia and chronically injured axons. A physiological basis for radicular pain of nerve root compression. Pain 1977; 3: 25-41.

83. Marshall LL, Trethewie ER, Curtain CC. Chemical radiculitis. A clinical, physiological and immunological study. Clin Orthop 1977; 129:61-67.

84. Pennington JB, McCarron RF, Laros GS. Identification of IgG in the canine intervertebral disc. Spine 1988; 13:909-912.

85. Nohara Y, Tohmura T. Fate of epidurally sequestrated disk. An immuno-histological study of herniated nucleus pulposus of the lumbar spine. From proceedings of the annual meeting. International Society for the Study of the Lumbar Spine, Marseilles. 1993.

86. Saal JS: The role of inflammation in lumbar pain. Spine 1995; 20: 1821-1827.

87. Kang JD, Georgescu HI, McIntyre-Larkin L et al. Herniated lumbar intervertebral discs spontaneously produce matrix metalloproteinases, nitric oxide, interleukin-6, and prostaglandin E2. Spine 1996; 21: 271-277.

88. Liu J, Roughley PJ, Mort JS. Identification of human intervertebral disc stromelysin and its involvement in matrix degradation. J Orthop Res 1991; 9: 568-575.

89. Kanemoto M, Hukuda S, Komiya Y et al. Immunohistochemical study of matrix metalloproteinase- 3 and tissue inhibitor of metalloproteinase-1 in human intervertebral discs. Spine 1996; 21: 1-8.

90. Brinkmann P. Injury of the annulus fibrosus and disc protrusions. An in vitro investigation on human lumbar discs. Spine 1986; 11: 149-153.

91. Donelson R, Aprill C, Medcalf R et al. A prospective study of centralization of lumbar and referred pain. A predictor of symptomatic disc and anular competence. Spine 1997; 22: 1115-1122.

92. Grubb SA, Lipscomb HJ, Guilford WB. The relative value of lumbar roentgenograms, metrizamide myelography and discography in the assessment of patients with chronic low- back syndrome. Spine 1987; 12: 282-286.

93. Gunzburg R, Parkinson R, Moore Met al. A cadaveric study comparing discography, magnetic resonance imaging, histology, and mechanical behavior of the human lumbar disc. Spine 1992; 17: 417-423.

94. Hickey DS, Aspden RM, Hukins WL et al. Analysis of magnetic resonance images from normal and degenerate lumbar intervertebral discs. Spine 1986; 11: 702708.

95. Chatani K, Kusaka Y, Mifune T et al. Topographic differences of $1 \mathrm{H}-\mathrm{NMR}$ relaxation times $(\mathrm{T} 1, \mathrm{~T} 2)$ in the normal intervertebral disc and its relationship to water content. Spine 1993; 18: 2271-2275.

96. Milette PC, Fontaine S, Lepanto L et al. Differentiating lumbar disc protrusions, disc bulges, and discs with normal contour but abnormal signal intensity. Magnetic resonance imaging with discographic correlations. Spine 1999; 24: 44-53.

97. Schneiderman G, Flannigan B, Kingston S et al. Magnetic resonance imaging in the diagnosis of disc degeneration. Correlation with discography. Spine 1987; 12: 276-281.

98. Kornberg M: Discography and magnetic resonance imaging in the diagnosis of lumbar disc disruption. Spine 1989; 14: 1368-1372.

99. Zucherman J, Derby R, Hsu K et al. Normal magnetic resonance imaging with abnormal discography. Spine 1988; 13: 1355-1359.

100. Buirski G. Magnetic resonance signal patterns of lumbar discs in patients with low back pain. A prospective study with discographic correlation. Spine 1992; 17: 1199-1204.

101. Horton WC, Daftari TK. Which disc as visualized by magnetic resonance imaging is actually a source of pain? A correlation between magnetic resonance imaging and discography. Spine 1992; 17:164-171.

102. Aprill C, Bogduk N. High-intensity zone. A diagnostic sign of painful lumbar disc on magnetic resonance imaging. Brit J Rad 1992; 65: 361-369.

103. Schellas KP, Pollei SR, Gundry CR et al. Lumbar disc high intensity zone. Correlation of magnetic resonance imaging and discography. Spine 1996; 21: 79-86.

104. Nguyen CM, Ho KC, Yu S et al. An experimental model to study contrast enhancement in MR imaging of the intervertebral disk. Amer J Radio 1989; 10: 811814.

105. Ross JS, Modic MT, Masaryk TJ. Tears of the annulus fibrosus assessment with Gd-DTPA-enhanced magnetic resonance imaging. AJNR 1989; 10: 1251-54.

106. Antti-Poika I, Soini J, Tallroth K et al. Clinical relevance of discography combined with CT scanning. A study of 100 patients. J Bone Joint Surg 1990; 72B: 480-485.

107. McCuthceon ME, Thompson WC. CT scanning of lumbar discography. A useful diagnostic adjunct. Spine 1986; 11: 257-259.

108. Fortin JD. Lumbar and thoracic discography with CT and MRI correlations. In: Lennard TA (ed). Physiatric Procedures. Philadelphia, Hanley and Belfus, 1995; 163-184. 
109. Merskey H, Bogduk N. Classification of Chronic Pain. Description of Chronic Pain Syndromes and Definitions of Pain Terms. Seattle, IASP Press, 1994; pp 180-181.

110. Maezawa S, Muro T. Pain provocation at lumbar discography as analyzed by computed tomography/discography. Spine 1992; 17: 1309-1315.

111. Moneta GB, Videman T, Kaivanto K et al. Reported pain during lumbar discography as a function of anular ruptures and disc degeneration. A reanalysis of 833 discograms. Spine 1994; 19:1968-1974.

112. Vanharanta H, Sachs BL, Spivey MA et al. The relationship of pain provocation to lumbar disc deterioration as seen by CT/discography. Spine 1987; 12: 295 298.

113. Weinstein JN, Claverie W, Gibson S. The pain of discography. Spine 1988; 13:1344-1348.

114. North American Spine Society. Position statement on discography. The Executive Committee of the North American Spine Society. Spine 1988; 13: 1343.

115. Guyer RD, Ohnmeiss DD. Lumbar discography. Position statement from the North American Spine Society Diagnostic and Therapeutic Committee. Spine 1995; 20: 2048-2059.

116. Sachs BL, Vanharanta H, Spivey MA et al. Dallas discogram description. A new classification of CT/ discography in low-back disorders. Spine 1987; 12: 287-294.

117. Guyer RD, Collier R, Stith WJ et al. Discitis after discography. Spine 1988; 13: 1352-1354.

118. Osti OL, Fraser RD, Vernon-Roberts. Discitis after discography. The role of prophylactic antibiotics. $J$ Bone Joint Surg 1990; 72: 271-274.

119. Junila J, Niinimaki T, Tervonen O. Epidural abscess after lumbar discography. A case report. Spine 1997; 22: 2191-2193.

120. Jull GA. Aspects of conservative therapy for the acutely painful lumbar disc. J Manual Med 1990; 5: 84-88.

121. Parkkola P, Rytokoski U, Kormano M. Magnetic resonance imaging of discs and trunk muscles in patients with chronic low back pain and healthy control subjects. Spine 1993; 18: 830-836.

122. Saal JA. Dynamic muscular stabilization in the nonoperative treatment of lumbar pain syndromes. Orthop Rev 1990; 19: 691-700.

123. Donelson R. The McKenzie approach to evaluating and treating low back pain. Orthop Rev 1990; 19: 681686.

124. Feffer HL. Therapeutic intradiscal hydrocortisone. A long term study. Clin Orthop 1969; 67:100-104.

125. Wilkinson HA, Schuman N. Intradiscal corticosteroids in the treatment of lumbar and cervical disc problems. Spine 1980; 5: 385-389.
126. Simmons JW, McMillin JN, Emery SF et al. Intradiscal steroids. A prospective double blind clinical trial. Spine 1992; 17:172-175.

127. Sluijter ME. The Use of Radiofrequency Lesions of the Communicating Ramus in the Treatment of Low Back Pain. In: Technique of Neurolysis. Racz GB (Ed), Boston, Kluwer Academic Publishing, 1989, pp 145160.

128. Sluijter ME. The use of radiofrequency lesions for pain relief in failed back patients. International Disability Studies. 1988; 10:37-43.

129. Saal JS, Saal JA. Management of chronic discogenic low back pain with a thermal intradiscal catheter. A preliminary report. Spine 2000; 25:382-388.

130. Fujimaki A, Crock HV. The results of 150 anterior lumbar interbody fusion operations performed by two surgeons in Australia. Clin Orthop 1982; 165: 164167.

131. Crock HV. Internal disc disruption: A challenge to disc prolapse 50 years on. Spine 1986; 11: 650-653.

132. Raugstad TS, Harbo K, Hogberg A et al. Anterior interbody fusion of the lumbar spine. Acta Orthop Scand 1982; 53: 561-565.

133. Blumenthal SL, Baker J, Dossett A et al. The role of anterior lumbar fusion for internal disc disruption. Spine 1988; 13: 566-569.

134. Grob D, Humke T. Translaminar screw fixation in the lumbar spine. Technique, indications, results. Eur Spine J 1998; 7: 178-186.

135. Linson MA, Williams H. Anterior and combined anteroposterior fusion for lumbar disc pain. A preliminary study. Spine 1991; 16: 143-145.

136. Loguidice VA, Johnson RG, Guyer RD et al. Anterior lumbar interbody fusion. Spine 1988; 13: 366-369.

137. Newman MH, Grinstead GL. Anterior lumbar interbody fusion for internal disc disruption. Spine 1992; 17: 831-833.

138. Wetzel FT, LaRocca H, Lowery GL et al. The treatment of lumbar spinal pain syndromes diagnosed by discography. Lumbar arthrodesis. Spine 1994; 19: 792-800.

139. Flynn JC, Hogue MA. Anterior fusion of the lumbar spine. J Bone Joint Surg 1979; 61: 1143-1150.

140. David T. Lumbar disc prosthesis. Surgical technique, indications and clinical results in 22 patients with a minimum of 12 months follow-up. Euro Spine J 1993; 1: 254-259.

141. Griffith SL, Shelokov AP, Buttner-Janz K et al. A multicenter retrospective study of the clinical results of the LINK SB Charite intervertebral prosthesis. The initial European experience. Spine 1994; 19: 18421849.

142. Lemaire JP, Skalli W, Lavaste F et al. Intervertebral disc prosthesis. Results and prospects for the year 2000. Clin Orthop Related Research 1997; 337: 64-76. 